\title{
Effects of reduced salinities on metamorphosis of a freshwater-tolerant sesarmid crab, Armases roberti: Is upstream migration in the megalopa stage constrained by increasing osmotic stress?
}

\author{
Gabriela Torres $^{\text {a,b,* }}$, Klaus Anger ${ }^{\text {a }}$, Luis Giménez ${ }^{\text {a,c }}$ \\ a Biologische Anstalt Helgoland, Foundation Alfred Wegener Institute for Polar and Marine Research, 27498 Helgoland, Germany \\ b AG Zoosystematik and Morphologie, Carl von Ossietzky Universität Oldenburg, 26129 Oldenburg, Germany \\ c Sección Oceanología, Facultad de Ciencias, Universidad de la República, 11400 Montevideo, Uruguay
}

Received 16 May 2006; received in revised form 11 June 2006; accepted 10 July 2006

\begin{abstract}
Numerous species of estuarine and freshwater-tolerant crabs show an "export strategy", i.e. an early larval downstream transport towards coastal marine waters, later zoeal development at higher salinities, and a return of the last larval stage, the megalopa, into estuaries or rivers. The speed and extent of the upstream migration of the megalopa through strong salinity gradients may be constrained by increasing hypo-osmotic stress. In an experimental laboratory study with Armases roberti, a freshwater-inhabiting sesarmid crab from the Caribbean region, we studied in the megalopa stage (after zoeal rearing at 25\%) the tolerance of reduced salinities.

In the first experiment, the larvae were exposed directly to various constant salinities (1-25\%). For the second experiment, they were transferred stepwise to strongly diluted media (within 6 days from $25 \%$ to $\leq 3 \%$ ), simulating differential scenarios of upstream migration into brackish or freshwater habitats.

When postmoult megalopae were exposed directly to salinities $\leq 3 \%$, they all died within $24 \mathrm{~h}$. A slightly higher salt concentration (5\%), however, allowed for considerable survival (46\%) through metamorphosis to the first juvenile crab stage. In treatments with continuous exposure to $10-15 \%$, as well as in a control group $(25 \%)$, survival to metamorphosis was significantly higher (83-96\%), and the average duration of development was shorter compared to 5\% (12-13 vs. 16 days). In the second experiment, with stepwise salinity reductions, gradual acclimation to decreasing osmotic pressures permitted a successful development to metamorphosis at $\leq 3 \%$ and even in freshwater $(<0.2 \%)$.

This strong physiological adaptability enables the megalopa of $A$. roberti to cross during its upstream migration, within a short time (6 days), strong osmotic gradients, so that metamorphosis is possible also in freshwater habitats where the conspecific adult crabs live. The speed of migration appears to be limited by physiological constraints related to changes in the capability for osmoregulation occurring during the course of the moulting cycle.
\end{abstract}

(C) 2006 Elsevier B.V. All rights reserved.

Keywords: Crustaceans; Estuarine; Larval biology; Limnic; Metamorphosis; Ontogenetic migrations; Salinity tolerance

\footnotetext{
* Corresponding author. Biologische Anstalt Helgoland, Foundation Alfred Wegener Institute for Polar and Marine Research, 27498 Helgoland, Germany. Tel.: +49 4725 819344; fax: +49 4725819369 .

E-mail address: gtorres@awi-bremerhaven.de (G. Torres).
} 


\section{Introduction}

Many animal species migrate to exploit additional food sources, to escape from predation, or to reproduce. These migrations may be constrained, however, by ecological barriers such as aquatic-terrestrial transitions, or by gradients in food availability, temperature, or salinity (Alerstram et al., 2003; Henningsson and Alerstram, 2005). Depending on the strength of such gradients and on the speed of their transition, the crossing of barriers can affect survival and individual performance.

Numerous aquatic animals living in coastal, estuarine, and adjacent freshwater environments, for example many species of crabs and other decapod crustaceans, perform ontogenetic migrations, because their early life-history stages are unable to tolerate highly variable and mostly reduced salinities typically occurring in the habitats of the adults (Anger, 2001, 2003; Forward and Tankersley, 2001). The newly hatched larvae of such species are rapidly transported out of the parental habitat, towards lower estuarine or coastal marine waters with more stable and on average higher salinities. In some species, e.g. in the blue crab, Callinectes sapidus (Forward and Tankersley, 2001), or in the Chinese mitten crab, Eriocheir sinensis (Rudnick et al., 2005), this "export strategy" (Strathmann, 1982) includes downstream migrations of the ovigerous females, which mitigate the exposure of newly hatched larvae to hypo-osmotic stress. Other species release their planktonic larvae into the habitat of the adult population, from where they are rapidly transported downstream by outflowing surface currents (for recent review, see Queiroga and Blanton, 2004). After zoeal development in near-shore or continental shelf waters, the megalopa and/or the early benthic juvenile stages migrate back to the parental habitat. This implies that the returning developmental stages of estuarine and riverine species are during their upstream migration exposed to increasingly diluted media, which requires an increasing tolerance of hypo-osmotic conditions.

Armases roberti (H. Milne Edwards), a freshwaterdwelling, semiterrestrial crab from the Caribbean region, may be a particularly suitable and extreme example for a riverine species with an export strategy. Being strong hyper-osmoregulators (Schubart and Diesel, 1998), the adult crabs live on riverbanks up to about $10 \mathrm{~km}$ away from the sea (Chace and Hobbs, 1969; Abele, 1992; Diesel and Schuh, 1998). Laboratory observations (Diesel and Schuh, 1998) suggest that the zoeae are released in freshwater, where they can survive for up to two days. Subsequently, however, the larvae must reach lower estuarine or coastal marine waters to develop at higher salinities through four zoeal stages. However, since only preliminary laboratory data (with constant salinities from hatching; Diesel and Schuh, 1998) and no field data are available, it has remained unknown, whether already the megalopa stage or only the subsequent benthic juveniles of this species are physiologically capable of migrating back into estuaries or rivers, crossing horizontal salinity gradients. In an experimental laboratory study, we therefore evaluated the salinity tolerance of the megalopa stage of $A$. roberti and, in particular, its capability to acclimatize to conditions of decreasing osmotic pressure during simulated upstream migrations, so that it can successfully develop to metamorphosis near to or in freshwater habitats, where the conspecific adults live.

\section{Materials and methods}

\subsection{Obtaining and rearing of larvae}

Ovigerous A. roberti were collected in March 2003 from the lower Rio Bueno River, northern Jamaica. At the collection site, the following water characteristics were measured with a "Combo $\mathrm{pH}$ and EC" (Hanna Instruments, Kehl, Germany) apparatus: water temperature: $23.8^{\circ} \mathrm{C}$, conductivity: $0.38 \mathrm{mS} / \mathrm{cm}$, total dissolved matter: $0.19 \%, \mathrm{pH}: 8.10$. Thereafter, the crabs were transported to the Helgoland Marine Biological Station, Helgoland, Germany, and maintained in aquaria with freshwater $(<0.2 \%)$ kept under constant conditions of temperature $\left(24^{\circ} \mathrm{C}\right)$ and a 12:12-h photoperiod. Food (frozen isopods, Idote $a \mathrm{sp}$.) and water were changed daily. After hatching in freshwater, zoeae were mass-reared in bowls with $400 \mathrm{ml}$ water (initial density 50 zoeae per bowl) at the same conditions of temperature and light, but at a salinity of $25 \%$ (considered as an optimal condition for zoeal development; Diesel and Schuh, 1998), until they reached metamorphosis to the megalopa stage. In daily intervals, water was changed and the larvae were fed ad libitum with freshly hatched brine shrimp (Artemia franciscana) nauplii. Different experimental salinities were obtained by diluting filtered seawater from the North Sea (ca. $1 \mu \mathrm{m}$ filter pore size; $32 \%$ ) with appropriate quantities of freshwater (total dissolved substances: $0.17 \mathrm{mg} / \mathrm{l}$, conductivity: $0.41 \mathrm{mS} / \mathrm{cm}$ ), and checked with a WTW (Weilheim, Germany) Cond-330i salinometer to the nearest $0.1 \%$.

\subsection{Experiments}

The experiments were started the first day after moulting from the zoea-IV stage. In the first experiment, megalopae were transferred from the salinity of previous zoeal rearing $(25 \%)$ to treatments with constant $15 \%$, $10 \%$, 5\%, 3\%o, or $1 \%$ o $(n=24$ megalopae each; for 
experimental design, see Fig. 1B-F). The mode of transference in these treatments is considered as "direct", because it was done within a single day (salinity decrements of $\leq 5 \%$, intervals of $2 \mathrm{~h}$ ). One group (A, Fig. $1 ; n=23$ megalopae) remained as control at constant $25 \%$. The purpose of this set of treatments was to estimate the limits of tolerance of various levels of continued hypo-osmotic stress in the megalopa stage.

In a second experiment, we tested the megalopal tolerance of rapidly increasing hypo-osmotic stress, with treatments $\mathrm{G}-\mathrm{J}$ (Fig. 1) simulating various scenarios of rapid upstream migration from the lower part of an estuary (moulting to the megalopa stage at 25\%o) into rivers or upper parts of an estuary. During the first 6 days of their moulting cycle, the megalopae were in these treatments transferred stepwise to increasingly dilute media (decrements of $\leq 5 \%$; intervals of $1-2$ days; final salinities: $3 \%$, $2 \%$, $1 \%$, or $0.17 \%$ ).

In all treatments, the megalopae were reared individually in $80-\mathrm{ml}$ vials with a piece of nylon gauze provided as substrate. Otherwise, rearing conditions (feeding, water change, temperature, light) were the same as in the zoeal stages (see above). The experiments were terminated when all individuals had either died or passed through metamorphosis to the first juvenile crab stage.

\subsection{Statistical analysis}

Data were analysed with separate factorial designs (Zar, 1996). The first design included the treatments A, $\mathrm{B}, \mathrm{C}$, and $\mathrm{D}$, i.e. without decreases in salinity after day 1 ;

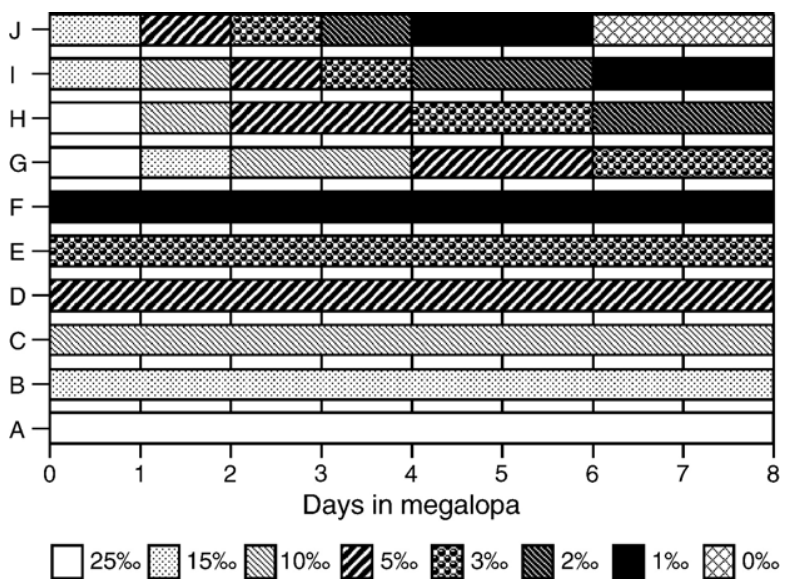

Fig. 1. Tests for salinity tolerance of the megalopa stage of Armases roberti, experimental design. (A) Control condition (constant salinity of $25 \%$ ); (B-F) treatments with direct transfer of megalopae from $25 \%$ to constantly reduced salinities $(15 \%, 10 \%, 5 \%, 3 \%, 1 \%)$; $(\mathrm{G}-\mathrm{J})$ treatments with stepwise reductions of salinity, simulating various speeds of megalopal upstream migration into estuaries and rivers. the treatments $\mathrm{E}$ and $\mathrm{F}$, with salinities $1 \%$ and $3 \%$, were not included in this analysis since mortality reached $100 \%$ within the first $24 \mathrm{~h}$ (see Results). The second design evaluated effects of treatments A, G, H, I, and J. Survival data were analyzed with log-linear analyses, while duration of development to the first juvenile stage with one-way ANOVA. For log-linear analyses, the significance of differences between the control treatment A and treatments $\mathrm{G}-\mathrm{J}$ were adjusted with the sequential Bonferroni method (Rice, 1989). For the ANOVAs, normality was checked with normal plots of residuals, heterogeneity of variance with Cochran's test.

\section{Results}

\subsection{Survival}

After direct exposure to very low salinities (1-3\%; treatments E, F; Fig. 1), all larvae died within 24 h. An exposure to $5 \%$ (treatment D) caused significantly higher mortality compared to all treatments with higher salinities $\left(\chi_{3}^{2}=17.2, p<0.001\right)$. Treatments A-C $(10-$ $25 \%$ ) allowed for $80-95 \%$ survival, while only $45 \%$ survived in treatment D (5\%). In the latter group, mortality was particularly high during the first $72 \mathrm{~h}$ of the megalopal moulting cycle (Fig. 2D). At 10-25\%, mortality occurred mostly after about 9 days or thereafter (Fig. 2A-C).

Exposure to different rates of decrease in salinity (treatments $\mathrm{G}-\mathrm{J})$ also affected survival $\left(\chi_{3}^{2}=11.0\right.$, $p<0.05)$. It exceeded $80 \%$ when the decrease in salinity was slow (treatment G, Fig. 2G), while minimum survival was observed in treatment $\mathrm{J}(42 \%$, Fig. $2 \mathrm{~J})$, where the decrease in salinity was faster. Mortality began mostly to increase conspicuously when salinity was decreased below 3\%o (Fig. 2G,H). After performing a Bonferroni correction, the survival in the control group A was not significantly different from that in treatments $\mathrm{G}\left(\chi_{2}^{2}=0.18, p>0.05\right)$ and $\mathrm{I}\left(\chi_{2}^{2}=3.96, p>0.025\right)$, but it was higher than in treatments $\mathrm{H}$ and $\mathrm{J}\left(\chi_{2}^{2}=11.46\right.$ and 17.32 , respectively, all $p<0.001$ ).

\subsection{Duration of development}

When salinity was either maintained constant at $25 \%$ o (control, A) or rapidly reduced during the first $24 \mathrm{~h}$ after moulting to the megalopa stage (treatments B-D), the duration of development increased with decreasing salinity (one-way ANOVA: $F_{3,69}=11.09, p<0.0001$ ). Individuals reared at 5\% showed a significantly longer duration of development than those reared at conditions of 10-25\% (Fig. 3A). 

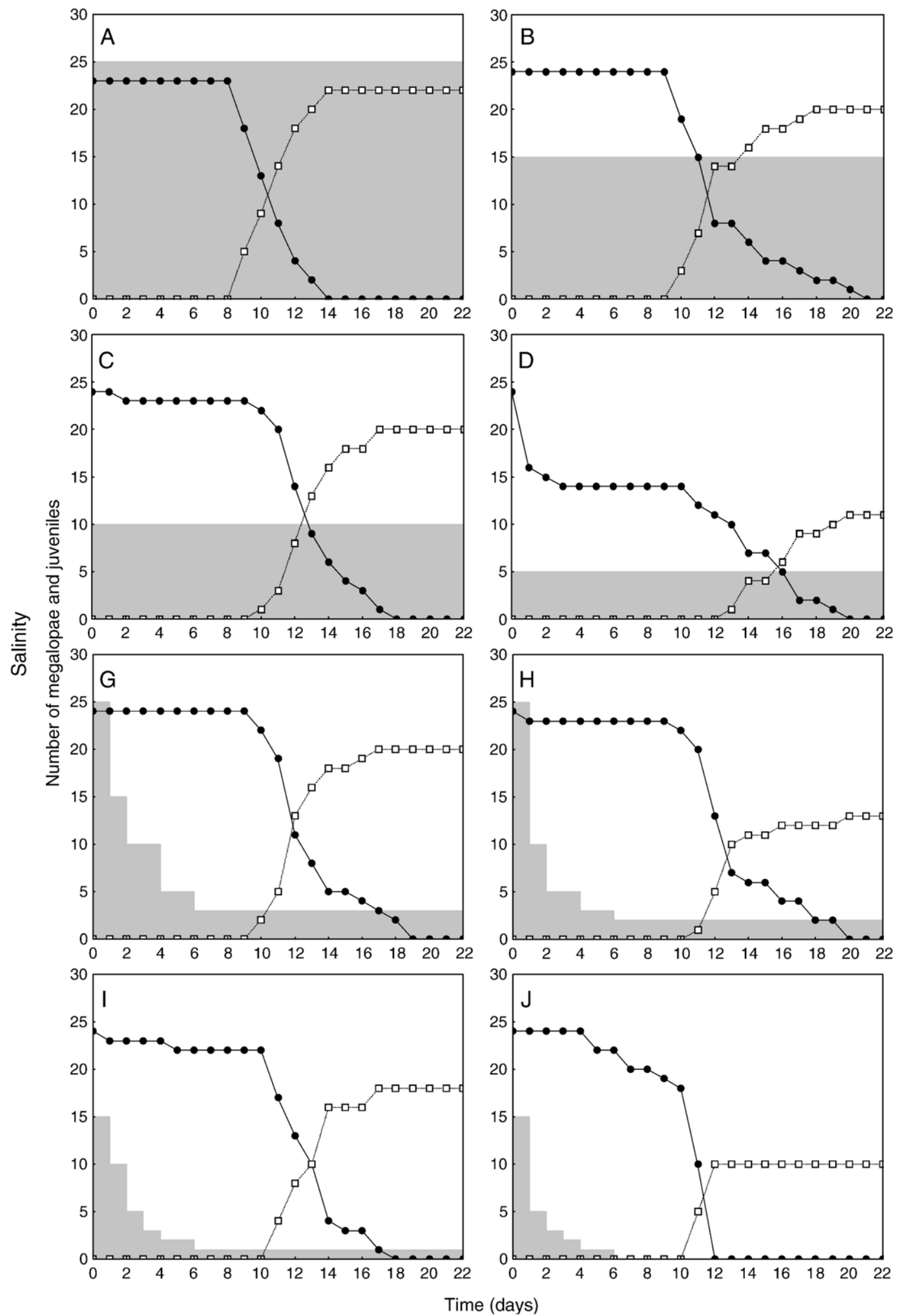

Fig. 2. Armases roberti, survival and development through the megalopa stage, during or after reductions of salinity (for experimental design, see Fig. 1); shaded areas, salinity (\%); filled circles, number of megalopae; open squares, numbers of first-stage crabs. 


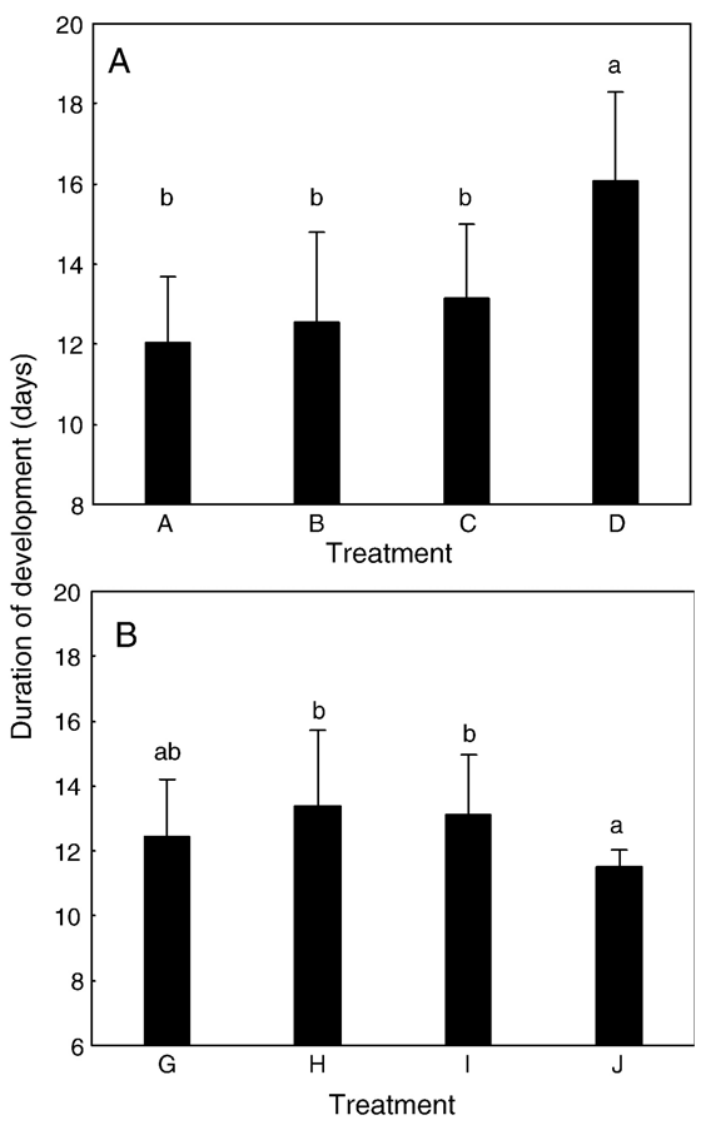

Fig. 3. Armases roberti, duration of development through the megalopa stage, during or after reductions of salinity (for experimental design, see Fig. 1); different letters indicate significant differences between treatments $(p<0.05$; Student-Newman-Keuls tests).

The duration of development during a stepwise reduction of salinity was ca. 1 day longer in treatments with a slower rate of decrease $(\mathrm{G}, \mathrm{H}, \mathrm{I})$ compared to the treatment with the fastest rate of decrease (J, Fig. 3B). Oneway ANOVA and a SNK post hoc test, including also the control group $\mathrm{A}$, revealed that these differences were statistically significant $\left(F_{4,78}=2.66, p<0.05\right)$, although the variances remained heterogeneous also after data transformation. A $t$-test with separate variance estimates, performed to test for differences between treatments $\mathrm{G}, \mathrm{H}$, I vs. treatment $\mathrm{J}$, showed also significant differences $(t=4.31, p<0.0001)$. The development time in the control group A was not significantly different from that in the other treatments with decreasing salinities (cf. Fig. 3A,B).

\section{Discussion}

Our results suggest that megalopal upstream migration and recruitment to freshwater-inhabiting popula- tions of $A$. roberti may be limited by physiological or developmental constraints. When the last larval stage was directly transferred from $25 \%$ to $5 \%$, it showed an increase of mortality and a longer duration of development. Most megalopae died in this treatment within the first few days, suggesting an osmotic shock. In treatments with a direct transfer from $25 \%$ o to $\leq 3 \%$, complete mortality occurred within only $24 \mathrm{~h}$.

Our experiment with stepwise reductions of salinity, by contrast, revealed that the megalopae are capable of gradual acclimation to low salinities. In treatment G, $80 \%$ of the megalopae were able to survive for an extended period (6-12 days) at a salinity as low as 3\%, followed by successful metamorphosis under this condition. In treatment $\mathrm{J}$, ca. $50 \%$ of the larvae survived even in freshwater through metamorphosis to the first juvenile crab stage. However, mortality increased during a fast decrease of salinity (compare treatments G, J), suggesting physiological limitations to the possible speed of upstream migration. Surprisingly, mean duration of development was shorter in the apparently stressful treatment $\mathrm{J}$ than in those with slower reductions of salinity (cf. H, I, Fig. 3B). This result might have been caused by selective mortality of physiologically weaker individuals, so that only the strongest and fastest developing larvae may have survived though metamorphosis, reducing the average value.

Our experimental observations suggest that migrations may initially be carried out at a low speed, allowing for gradual acclimation. During the early postmoult phase, decapod larvae are osmo-conformers rather than osmo-regulators, mainly due to high permeability of the initially thin cuticle (Charmantier, 1998). During this period, the capacity for osmoregulation may therefore be too weak to compensate for passive losses of ions and intrusion of water in dilute media and, as a consequence, the megalopae may initially be more vulnerable to osmotic stress than during later stages of the moulting cycle (intermoult, premoult). The pace of megalopal upstream migrations into oligohaline and freshwater environments, where the adult populations live, may thus be physiologically limited by constraints related to the moulting cycle.

\section{Acknowledgements}

We thank U. Nettelmann and K. Boos for help in the experiments. G.T. acknowledges the Deutscher Akademischer Austausch dienst, DAAD (Bonn, Germany) for funding this study as a part of her doctoral dissertation, and L.G. the Alexander-von-Humboldt Foundation (Bonn, Germany) for a postdoctoral research grant. 
The experiments comply with the current German animal and manipulation laws. [SS]

\section{References}

Abele, L.G., 1992. A review of the grapsid crab genus Sesarma (Crustacea: Decapoda: Grapsidae) in America, with the description of a new genus. Smithson. Contrib. Zool. 527, 1-60.

Alerstram, T., Hedenström, A., Åkesson, S., 2003. Long-distance migration: evolution and determinants. Oikos 103, 247-260.

Anger, K., 2001. The Biology of Decapod Crustacean Larvae. Crustacean Issues, vol. 14. Swets and Zeitlinger, Lisse.

Anger, K., 2003. Salinity as a key parameter in the larval biology of decapod crustaceans. Invertebr. Reprod. Dev. 43, 29-45.

Chace, F.A., Hobbs, H.H., 1969. The freshwater and terrestrial decapod crustaceans of the West Indies with special reference to Dominica. Bull. National Museum U.S., vol. 292, pp. 1-298.

Charmantier, G., 1998. Ontogeny of osmoregulation in crustaceans: a review. Invertebr. Reprod. Dev. 33, 177-190.

Diesel, R., Schuh, M., 1998. Effects of salinity and starvation on larval development of the crabs Armases ricordi and A. roberti (Decapoda: Grapsidae) from Jamaica, with notes on the biology and ecology of adults. J. Crustac. Biol. 18, 423-436.
Forward Jr., R.B., Tankersley, R.A., 2001. Selective tidal stream transport of marine animals. Oceanogr. Mar. Biol. Annu. Rev. 39, 305-353.

Henningsson, S., Alerstram, T., 2005. Barriers and distances as determinants for the evolution of bird migration links: the arctic shorebird system. Proc. R. Soc. B 272, 2251-2258.

Queiroga, H., Blanton, J., 2004. Interactions between behaviour and physical forcing in the control of horizontal transport of decapod larvae. Adv. Mar. Biol. 47, 107-214.

Rice, W., 1989. Analyzing tables of statistical tests. Evolution 43, 223-225.

Rudnick, D., Veldhuizen, T., Tullis, R., Culver, C., Hieb, K., Tsukimura, B., 2005. A life history model for the San Francisco Estuary population of the Chinese mitten crab, Eriocheir sinensis (Decapoda: Grapsoidea). Biological Invasions 7, 333-350.

Schubart, C.D., Diesel, R., 1998. Osmoregulatory capacities and penetration into terrestrial habitats: a comparative study of Jamaican crabs of the genus Armases Abele, 1992 (Brachyura: Grapsidae: Sesarminae). Bull. Mar. Sci. 62 (3), 743-752.

Strathmann, R.R., 1982. Selection for retention or export of larvae in estuaries. In: Kennedy, V.S. (Ed.), Estuarine Comparisons. Academic Press, San Diego, pp. 521-535.

Zar, J., 1996. Biostatistical Analysis. Prentice-Hall, London. 